\title{
Assessment of internal mammary artery injury after blunt chest trauma: a literature review
}

\author{
Jin-ming $\mathrm{CHEN}^{1}$, Jin $\mathrm{LV}^{2}$, Kai MA ${ }^{3}$, Jing YAN ${ }^{\dagger \neq 2}$ \\ ( ${ }^{1}$ Department of Emergency Medicine, the Second Affiliated Hospital, School of Medicine, Zhejiang University, Hangzhou 310009, China) \\ ( ${ }^{2}$ Department of Emergency Medicine, Zhejiang Hospital, Hangzhou 310053, China) \\ ( ${ }^{3}$ Department of Thoracic Surgery, the Affiliated Hospital, School of Medicine, Qingdao University, Qingdao 266003, China) \\ †E-mail: zjicu@vip.163.com \\ Received Apr. 6, 2014; Revision accepted July 20, 2014; Crosschecked Sept. 20, 2014
}

\begin{abstract}
The occurrence, bleeding, and treatment of internal mammary artery (IMA) injury after blunt chest trauma have not been well described in the literature. We reviewed articles published from July 1977 to February 2014 describing IMA injury after blunt chest trauma in 49 patients. There was a predominant incidence in males and on the left side. Blunt trauma to the IMA can cause anterior mediastinal hematoma, hemothorax, pseudoaneurysm, arteriovenous fistula, and extra-pleural hematoma. Of the 49 patients studied, 20 underwent embolization, 22 underwent surgical operation, 4 were managed by clinical observation, and 3 had undescribed treatment. Different parts and extents of IMA injury, adjacent vein injury, as well as the integrity of the pleura determined differences in bleeding modality. Prompt diagnosis, complete hemostasis, aggressive resuscitation, and multidisciplinary teams are recommended for patients with IMA injury.
\end{abstract}

Key words: Internal mammary artery injury, Blunt chest trauma, Bleeding, Treatment doi:10.1631/jzus.B1400098 Document code: A CLC number: R641

\section{Introduction}

Injury to the internal mammary artery (IMA) after blunt chest trauma is rarely reported in the literature. However, prompt diagnosis and treatment are necessary, as it can be associated with severe hypovolemic shock and on-going blood loss.

This is a review of IMA injury secondary to blunt chest trauma. This should help to reduce misdiagnosis and avoid potentially life-threatening sequelae when such patients present to the emergency room. We also discuss the etiology, diagnosis, and management of IMA injuries following blunt trauma.

\section{Literature review}

We conducted an extensive MEDLINE search

\footnotetext{
${ }^{\ddagger}$ Corresponding author

(C) Zhejiang University and Springer-Verlag Berlin Heidelberg 2014
}

for articles published from July 1977 to February 2014, based on the keywords "internal mammary artery injury" and "blunt chest trauma". We found 26 case reports and 3 original articles, providing only 49 cases over the past 30 years or more. Of the three original articles, 1,9 , and 8 cases were reported, respectively. Twenty-nine cases, as complete reports, were compared by a retrospective review. Data regarding the patients' age, sex, shock, side, bleeding, treatment, and outcome were extracted (Table 1). In addition, two case reports (Bruneton et al., 1977; Tomcsányi et al., 1978) without the inclusion of original data and the three original articles (Mohlala et al., 1989; Chen et al., 2001; Whigham et al., 2002) without individual data records were also analyzed.

The review of the literature showed that IMA injury is extremely rare, with only 49 cases being reported over 37 years. According to the cumulative data, the mean age of the patients was 41 years (range 16-78 years). 
Table 1 Clinical characteristics of the reported 29 cases

\begin{tabular}{|c|c|c|c|c|c|c|c|}
\hline Study & $\begin{array}{c}\text { Age } \\
\text { (year) }\end{array}$ & Gender & Shock & Side & Comorbidity & Treatment & Outcome \\
\hline $\begin{array}{l}\text { Betsch et al., } \\
2010\end{array}$ & 41 & Male & No & Bilateral & $\mathrm{AMH}$, right hemothorax & Embolization & Survived \\
\hline \multirow{4}{*}{$\begin{array}{l}\text { Braatz et al., } \\
2001\end{array}$} & 26 & Male & No & Bilateral & AMH, left hemothorax & Operation & Survived \\
\hline & 40 & Male & Yes & Left & AMH, cardiac compression & Operation & Died \\
\hline & 36 & Female & Yes & Left & $\begin{array}{l}\text { AMH, RFs, splenectomy, PL, } \\
\text { II, PC, pneumothorax }\end{array}$ & Operation & Died \\
\hline & 53 & Male & No & Left & $\begin{array}{l}\text { AMH, pneumothorax, left clavic- } \\
\text { ular fracture, BPE }\end{array}$ & Operation & Survived \\
\hline $\begin{array}{l}\text { Cagini et al., } \\
2013\end{array}$ & 64 & Male & No & Left & AMH, SF, hemothorax, PC & Embolization & Survived \\
\hline $\begin{array}{l}\text { Cheng et al., } \\
2010\end{array}$ & 35 & Female & No & Left & $\begin{array}{l}\text { AMH, liver laceration, SF, II, } \\
\text { subarachnoid hemorrhage }\end{array}$ & Operation & Survived \\
\hline $\begin{array}{l}\text { Hagiwara et al., } \\
2010\end{array}$ & 77 & Male & No & Bilateral & $\begin{array}{l}\text { AMH, bilateral hemothorax, } \\
\text { cardiac compression }\end{array}$ & Embolization & Survived \\
\hline $\begin{array}{l}\text { Husted et al., } \\
1982\end{array}$ & 29 & Male & Yes & Right & $\mathrm{AMH}$ & Embolization & Survived \\
\hline Irgau et al., 1995 & 53 & Male & No & Left & $\begin{array}{l}\text { AMH, hemopneumothorax, car- } \\
\text { diac tamponade, SF }\end{array}$ & Operation & Survived \\
\hline Ishida et al., 2013 & 78 & Male & Yes & Right & Right hemothorax, RFs & Embolization & Survived \\
\hline $\begin{array}{l}\text { Ishikawa and } \\
\text { Brown, } 1977\end{array}$ & 25 & Female & No & Left & Aneurysm, AF & Operation & Survived \\
\hline Ito et al., 2005 & 67 & Male & Yes & Left & $\begin{array}{l}\text { Bilateral pneumohemothorax, } \\
\text { C6 fracture, CCI, AF, PC }\end{array}$ & Embolization & Survived \\
\hline \multirow{3}{*}{$\begin{array}{l}\text { Kawamura et al., } \\
2006\end{array}$} & 57 & Male & Yes & Bilateral & AMH, hemothorax & Embolization & Died \\
\hline & 25 & Female & Yes & Bilateral & $\begin{array}{l}\text { AMH, kidney laceration, cardiac } \\
\text { tamponade, MF }\end{array}$ & Embolization & Survived \\
\hline & 26 & Female & Yes & Left & $\begin{array}{l}\text { AMH, hemopneumothorax, } \\
\text { pseudoaneurysm, RAI, MF }\end{array}$ & Embolization & Survived \\
\hline Kim et al., 2012 & 40 & Male & Yes & Left & $\mathrm{AMH}$, cardiac tamponade & Operation & Survived \\
\hline Kwon et al., 2005 & 30 & Male & Yes & Left & $\begin{array}{l}\text { AMH, cardiac compression, } \\
\text { left hemothorax }\end{array}$ & Operation & Survived \\
\hline Ma et al., 2012 & 44 & Male & No & Right & Pseudoaneurysm & Operation & Survived \\
\hline $\begin{array}{l}\text { Machin and Lau, } \\
1995\end{array}$ & 21 & Male & No & Left & Extra-pleural hematoma, DCCJ & Operation & Survived \\
\hline $\begin{array}{l}\text { Madoff et al. } \\
2000\end{array}$ & 16 & Male & No & Right & AMH, pseudoaneurysm & Operation & Survived \\
\hline $\begin{array}{l}\text { Nomori et al., } \\
2003\end{array}$ & 52 & Male & Yes & Bilateral & $\begin{array}{l}\text { AMH, bilateral hemothorax, } \\
\text { RF, SF }\end{array}$ & Operation & Survived \\
\hline Patel et al., 2009 & 52 & Female & No & Left & Pseudoaneurysm & Embolization & Survived \\
\hline $\begin{array}{l}\text { Radanović et al., } \\
1996\end{array}$ & 26 & Male & Yes & Left & $\begin{array}{l}\text { Double false aneurysm, PL, } \\
\text { chest hematoma, plenectomy }\end{array}$ & Embolization & Survived \\
\hline Smith et al., 1982 & 35 & Male & No & Left & Pseudoaneurysm, RFs & Embolization & Survived \\
\hline $\begin{array}{l}\text { Suh and Kim, } \\
2008\end{array}$ & 59 & Female & No & Left & Extra-thoracic hematoma & Operation & Survived \\
\hline $\begin{array}{l}\text { Takeshima et al., } \\
1997\end{array}$ & 21 & Female & No & Left & AMH, pseudoaneurysm & Operation & Survived \\
\hline $\begin{array}{l}\text { Wilkinson et al., } \\
1993\end{array}$ & 29 & Male & Yes & Right & False aneurysm, RFs & Operation & Survived \\
\hline Yeh et al., 2009 & 19 & Male & No & Bilateral & AMH, RAVC, PCC, SF & Embolization & Survived \\
\hline
\end{tabular}

AF: arteriovenous fistula; AMH: anterior mediastinal hematoma; BPE: bilateral pleural effusions; CCI: cervical cord injury; DCCJ: dislocated costo-chondral joint; II: intracranial injury; MF: multiple fracture; PC: pulmonary contusion; PCC: pulmonary contusion and consolidation; PL: pulmonary laceration; RAI: renal artery injury; RAVC: ruptured aortic valve cusp; RF: rib fracture; SF: sternum fracture 
There was a predominant incidence in males, with a male-to-female ratio of $21: 8$. Thirteen ( $45 \%)$ of the 29 patients presented with symptoms of shock. We also found that there was a predominant incidence on the left side, with a left-to-right-to-bilateral side ratio of 17:5:7. The diagnostic findings were anterior mediastinal hematoma (AMH) (19 patients, 65.5\%), hemothorax (11 patients, 37.9\%), pseudoaneurysm (8 patients, 27.6\%), extra-pleural hematoma ( 2 patients, $6.9 \%)$, and arteriovenous fistula (2 patients, $6.9 \%$ ). In addition, AMH combined with hemothorax ( 9 patients, 31\%), AMH combined with pseudoaneurysm (3 patients, 10.3\%), pseudoaneurysm combined with hemothorax (1 patient, $3.4 \%$ ), and arteriovenous fistula combined with hemothorax (1 patient, $3.4 \%$ ) were found. Other diagnostic findings included pneumothorax (5 patients, $17.2 \%$ ), rib fracture (5 patients, 17.2\%), sternum fracture (5 patients, $17.2 \%$ ), and cardiac tamponade (6 patients, $20.7 \%$ ). Of the 29 patients, 13 (44.8\%) underwent transcatheter embolotherapy. Sixteen patients $(55.2 \%)$ were managed by a surgical team. Three patients $(10.3 \%)$ died as a result of the blunt chest trauma with a large $\mathrm{AMH}$, a coexistent severely extensive intracranial injury, or a left cerebellar hemorrhage, respectively. Nine $(31.0 \%)$ were motorcycle collisions and four (13.8\%) were motor vehicle (Table 2).

In the two case reports without the inclusion of original data, Bruneton et al. (1977) and Tomcsányi et al. (1978) reported two arteriovenous fistulae of the IMA injury, respectively. In the three original articles

Table 2 Causes of the reported 29 cases

\begin{tabular}{lcc}
\hline \multirow{2}{*}{ Cause } & \multicolumn{2}{c}{ IMA injury } \\
\cline { 2 - 3 } & Case number Percentage (\%) \\
\hline Motorcycle collision & 9 & 31.0 \\
Automobile collision & 4 & 13.8 \\
MCWAP & 1 & 3.4 \\
Rugby tackle & 1 & 3.4 \\
Multiple explosive injury & 1 & 3.4 \\
Jump from a 40-foot wall & 1 & 3.4 \\
Soccer game collision & 1 & 3.4 \\
Pounding chest & 3 & 10.3 \\
Traffic accident & 3 & 10.3 \\
Hit by a heavy burden & 2 & 6.9 \\
Fell from a height & 3 & 10.3 \\
\hline
\end{tabular}

IMA: internal mammary artery; MCWAP: midair collision with another parachutist without individual data records, Mohlala et al. (1989) reported 10 patients ( 8 with blunt wounds and 2 with stab injuries) with IMA injuries. The 8 blunt trauma cases all produced a well-circumscribed hematoma in the extra-pleural plane: 5 patients underwent operative exploration and 3 were managed conservatively with observation. Chen et al. (2001) reviewed the thoracic aortograms of 166 patients examined at their institution (Wake Forest University School of Medicine, USA) from May 1995 to May 1999 after blunt thoracic trauma. Of the 166 patients, 24 had aortic or arch branch vessel injuries; isolated aortic injury occurred in 15 patients (9\%), branch vessel injury occurred in 9 patients (5\%), and IMA injury occurred in 1 patient $(0.6 \%)$ in whom pseudoaneurysm was found. Whigham et al. (2002) studied 18 patients (9 with blunt trauma and 9 with penetrating injuries) with IMA injuries. The radiographic findings of the chest were mediastinal hematoma (3 patients), hemothorax (13 patients), and pneumothorax (2 patients). Of the 9 patients with blunt trauma, the age ranged 23-71 years (mean 42 years); the male-tofemale ratio was 7:2; 8 patients were victims of motor vehicle accidents; 7 underwent embolization, 1 underwent surgical ligation, and 1 was managed by non-operative observation. Complications included multisystem injury (5 patients), fatal-cardiac contusion (1 patient), and delayed hemothorax (1 patient). Two patients had no complications (Table 3 ).

\section{Discussion}

Blunt chest trauma to the IMA is a perplexing problem, which is difficult to diagnose promptly. Yet, successful diagnosis and treatment are two of the most challenging tasks in trauma surgery. When an IMA injury goes undetected, the consequences are serious because of the occurrence of lethal shock in $45 \%$ of patients with IMA injury. Therefore, it is very important to investigate the occurrence, nature of bleeding, and treatment in IMA injury.

For IMA injuries, these are more likely to be in males, and affect the left side. The leading causes of IMA injuries are motorcycle and automobile accidents. In traumatic aortic injuries, the site of rupture in all cases reviewed was in the region of the isthmus, just distal to the left subclavian artery (Rittenhouse 
Table 3 Summary of the nine cases reported by Whigham et al. (2002)

\begin{tabular}{cccccc}
\hline Case & Age (year) & Gender & Mechanism & Therapy & Complication \\
\hline 1 & 48 & Male & Motor vehicle accident & Embolization & None \\
2 & 60 & Male & Motor vehicle accident & Embolization & Multisystem injury \\
3 & 23 & Male & Motor vehicle accident & Embolization & Multisystem injury \\
4 & 41 & Female & Motor vehicle accident & Embolization & Died-cardiac contusion \\
5 & 34 & Male & Motor vehicle accident & Embolization & Multisystem injury \\
6 & 30 & Male & Motor vehicle accident/penetrating & Operation & Delayed hemothorax \\
7 & 23 & Male & Motor vehicle accident & Observation & Multisystem injury \\
8 & 71 & Female & Motor vehicle accident & Embolization & None \\
9 & 44 & Male & Auto-pedestrian & Embolization & Multisystem injury \\
\hline
\end{tabular}

et al., 1969). Chen et al. (2001) reported that $85 \%$ of the injured branch vessels directly originated from the aortic arch. Thus, the greater incidence of the left IMA may be correlated with the anatomic structure being closer to the aortic arch.

The IMA arises from the concavity of the first part of the subclavian artery and immediately passes downwards, forwards and medially, lying upon the pleura in the upper intercostal spaces up to the third costal cartilage; after this, it continues anterior to the transversus thoracis muscle to end in the sixth intercostal space by dividing into the superior epigastric and musculophrenic arteries (McVay, 1984). There are five main locations of bleeding following IMA injury: $\mathrm{AMH}$, hemothorax, pseudoaneurysm, arteriovenous fistula, and extra-pleural hematoma. We found AMH combined with hemothorax or pseudoaneurysm, as well as hemothorax combined with pseudoaneurysm or arteriovenous fistula; however, all extra-pleural hematomas were found without other complications. This implies a different mechanism of formation for extra-pleural hematoma. Disruption of the IMA produces a hematoma confined by the parietal pleura and/or the transversus thoracis muscle (Mohlala et al., 1989). In addition, the parietal pleura remains intact, and blood cannot escape into the pleural cavity. Thus, different parts and extents of IMA injury, adjacent vein injury, as well as the integrity of the pleura, determine differences in bleeding modality.

Of the 49 patients studied, 20 underwent embolization, 22 underwent surgical operation, 4 were managed by clinical observation, and 3 had treatment which were not detailed. Three patients died as an indirect result of IMA injury. The success rates for the patients in the embolization group and surgically managed group were $91.6 \%$ and $66.0 \%$, respectively (Whigham et al., 2002). Embolotherapy offers an effective, efficient, and safe alternative to conventional surgical management of IMA injures. Although IMA transection can sometimes retract and achieve temporary hemostasis during periods of hypotension and arterial spasm, renewed bleeding may occur once the patient is resuscitated (Whigham et al., 2002). The IMA blood flow averages $150 \mathrm{ml} / \mathrm{min}$, which can result in a life-threatening hemorrhage within a few minutes (Ritter and Chang, 1995). Rashid et al. (2001) demonstrated that early thoracotomy is important for salvaging patients with chest-wall vascular injury. Therefore, prompt diagnosis, complete hemostasis, and aggressive resuscitation are recommended. Although embolization has a high success rate, about $45 \%$ of patients require surgical management to control bleeding. Multidisciplinary teams are recommended for patients with IMA injury, especially when the IMA injury is accompanied by a severe shock.

Active extravasation of contrast material can be detected in trauma patients who are physiologically stable enough to undergo contrast-enhanced computed tomography (CT) of the thorax. CT accurately shows the anatomic location of bleeding and indicates the probable vascular origin. $\mathrm{CT}$, therefore, can be used as a guide for angiographic or surgical intervention (Shanmuganathan et al., 1993). In addition, multidetector CT angiography provides a timeefficient method for directing and planning therapy for patients with acute bleeding. The additional information provided by multidetector $\mathrm{CT}$ angiography before attempts at therapeutic angiographic procedures leads to faster selective catheterization of bleeding vessels, thereby facilitating embolization (Geffroy et al., 2011). However, digital subtraction 
angiography has long been the gold standard for the detection of active bleeding in patients. If a hemorrhage source is identified, superselective catheterization followed by transcatheter microcoil embolization is usually the most effective means of successfully controlling hemorrhage, while minimizing potential complications (Walker et al., 2012). Patients who are actively bleeding from the IMA should be managed with angiographic embolization as soon as possible, especially high-risk patients with shock. Angiographic embolization should always be considered before surgery.

\section{Conclusions}

Blunt trauma to the IMA is very rare and can cause AMH, hemothorax, pseudoaneurysm, arteriovenous fistula, and extra-pleural hematoma. There is a predominant incidence in males and on the left side. Different parts and extents of IMA injury, adjacent vein injury, as well as the integrity of the pleura, determine differences in bleeding modality. Embolotherapy offers an effective alternative to conventional operation of IMA injures. Prompt diagnosis, complete hemostasis, aggressive resuscitation, and multidisciplinary teams are recommended for patients with IMA injury, especially when it is accompanied by a severe shock.

\section{Compliance with ethics guidelines}

Jin-ming CHEN, Jin LV, Kai MA, and Jing YAN declare that they have no conflict of interest.

This article does not contain any studies with human or animal subjects performed by any of the authors.

\section{References}

Betsch, M., Jungbluth, P., Grassmann, J.P., et al., 2010. Bilateral injuries of the internal mammary artery following blunt thoracic trauma. Der Unfallchirurg, 113(9):757-760. [doi:10.1007/s00113-010-1804-x]

Braatz, T., Mirvis, S.E., Killeen, K., et al., 2001. CT diagnosis of internal mammary artery injury caused by blunt trauma. Clin. Radiol., 56(2):120-123. [doi:10.1053/crad.2000.0572]

Bruneton, J.N., Drouillard, J., Rabin, A., et al., 1977. Arteriovenous fistulae of internal mammary origin. Contribution of angiography in a post-traumatic case (author's transl). Ann. Radiol., 20(6):573-576.

Cagini, L., Vannucci, J., Scialpi, M., et al., 2013. Diagnosis and endovascular treatment of an internal mammary artery injury. J. Emerg. Med., 44(1):e117-e119. [doi:10. 1016/j.jemermed.2012.02.035]

Chen, M.Y., Regan, J.D., D'Amore, M.J., et al., 2001. Role of angiography in the detection of aortic branch vessel injury after blunt thoracic trauma. J. Trauma Injury Infect. Crit. Care, 51(6):1166-1171. [doi:10.1097/00005373-20011 2000-00024]

Cheng, Y.C., Chen, C.W., Lee, W.C., et al., 2010. Retrosternal hemomediastinum caused by internal mammary artery injury: a case report and review of the literature. J. Emerg. Crit. Care. Med., 21(2):83-87.

Geffroy, Y., Rodallec, M.H., Boulay-Coletta, I., et al., 2011. Multidetector CT angiography in acute gastrointestinal bleeding: why, when, and how. Radiographics, 31(3): E35-E46. [doi:10.1148/rg.313105206]

Hagiwara, S., Ogino, T., Morimura, M., et al., 2010. Bilateral internal mammary artery injury without fracture of the chest following a traffic accident. Kitakanto Med. J., 60(2):159-162. [doi:10.2974/kmj.60.159]

Husted, J.W., Stock, J.R., Manella, W.J., 1982. Traumatic anterior mediastinal hemorrhage: control by internal mammary artery embolization. Cardiovasc. Intervent. Radiol., 5(5):268-270. [doi:10.1007/BF02565410]

Irgau, I., Fulda, G.J., Hailstone, D., et al., 1995. Internal mammary artery injury, anterior mediastinal hematoma, and cardiac compromise after blunt chest trauma. $J$. Trauma, 39(5):1018-1021. [doi:10.1097/00005373-1995 11000-00038]

Ishida, I., Oura, H., Kawakami, T., et al., 2013. Patient with massive hemothorax due to blunt trauma saved by transcatheter arterial embolization. Kyobu Geka, 66(6): 445-448.

Ishikawa, T., Brown, G.R., 1977. Traumatic arteriovenous fistula of the internal mammary artery. J. Trauma, 17(12): 978-980. [doi:10.1097/00005373-197712000-00017]

Ito, T., Sakamoto, T., Norio, H., et al., 2005. An arteriovenous fistula between the internal mammary artery and the pulmonary vein following blunt chest trauma. Cardiovasc. Intervent. Radiol., 28(1):120-123. [doi:10.1007/s00270004-9111-y]

Kawamura, S., Nishimaki, H., Takigawa, M., et al., 2006. Internal mammary artery injury after blunt chest trauma treated with transcatheter arterial embolization. J. Trauma Injury Infect. Crit. Care, 61(6):1536-1539. [doi:10. 1097/01.ta.0000243201.49744.fc]

Kim, Y.H., Kwon, J.B., Park, C.B., et al., 2012. Extrapericardial cardiac tamponade by a retrosternal haematoma after blunt chest trauma. Eur. J. Cardio-Thorac. Surg., 41(4): 958. [doi:10.1093/ejcts/ezr116]

Kwon, O.Y., Chung, S.P., Yoo, I.S., et al., 2005. Delayed presentation of internal mammary artery rupture after blunt chest trauma: characteristic CT and plain X ray findings. Emerg. Med. J., 22(9):664-665. [doi:10.1136/ emj.2003.013607]

Ma, R.Y., Yang, Z.Y., Jian, Z., et al., 2012. Traumatic aneurysm of the right internal thoracic artery. Ann. Thorac. Surg., 93(4):e107. [doi:10.1016/j.athoracsur.2011.11.071]

Machin, V.G., Lau, O.J., 1995. Extra-pleural haematoma secondary to blunt chest trauma. An unusual presentation. Eur. J. Cardio-Thorac. Surg., 9(2):109-110. [doi:10. 1016/S1010-7940(05)80031-4]

Madoff, D.C., Brathwaite, C.E., Manzione, J.V., et al., 2000. 
Coexistent rupture of the proximal right subclavian and internal mammary arteries after blunt chest trauma. $J$. Trauma Injury Infect. Crit. Care, 48(3):521-524. [doi:10. 1097/00005373-200003000-00026]

McVay, C.B., 1984. Anson \& McVay's Surgical Anatomy. WB Saunders, Philadelphia, p.347-349.

Mohlala, M.L., Vanker, E.A., Ballaram, R.S., 1989. Internal mammary artery haematoma. S. Afr. J. Surg., 27(4): 136-138.

Nomori, H., Ootsuka, T., Horio, H., et al., 2003. Bilateral internal thoracic artery injury induced by blunt trauma. Jpn. J. Thorac. Cardiovasc. Surg., 51(5):214-216. [doi:10. 1007/s11748-003-0036-1]

Patel, K., Kimbrell, B.J., Marx, M.V., et al., 2009. Angiographic embolization of an expanding breast hematoma after blunt trauma: a novel approach to a rare injury. $J$. Trauma Injury Infect. Crit. Care, 67(1):E14-E16. [doi:10. 1097/TA.0b013e3180485cc4]

Radanović, B., Simunić, S., Oberman, B.B., et al., 1996. Arteriovenous fistula of the internal mammary artery (combat injury): transcatheter intravascular coil occlusion Eur. Radiol., 6(2):236-238. [doi:10.1007/BF00181158]

Rashid, M.A., Wikström, T., Ortenwall, P., 2001. Thoracic vascular injuries: a major problem in trauma. Scand. Cardiovasc. J., 35(4):285-287. [doi:10.1080/1401743015 2581413]

Rittenhouse, E.A., Dillard, D.H., Winterscheid, L.C., et al., 1969. Traumatic rupture of the thoracic aorta: a review of the literature and a report of five cases with attention to special problems in early surgical management. Ann. Surg., 170(1): 87-100. [doi:10.1097/00000658-196907000-00010]

Ritter, D.C., Chang, F.C., 1995. Delayed hemothorax resulting from stab wounds to the internal mammary artery. $J$. Trauma Injury Infect. Crit. Care, 39(3):586-589. [doi:10. 1097/00005373-199509000-00032]
Shanmuganathan, K., Mirvis, S.E., Sover, E.R., 1993. Value of contrast-enhanced $\mathrm{CT}$ in detecting active hemorrhage in patients with blunt abdominal or pelvic trauma. Am. J. Roentgenol., 161(1):65-69. [doi:10.2214/ajr.161.1. 8517323]

Smith, D.C., Senac, M.O., Bailey, L.L., 1982. Embolotherapy of a ruptured internal mammary artery secondary to blunt chest trauma. J. Trauma Injury Infect. Crit. Care, 22(4): 333-335. [doi:10.1097/00005373-198204000-00014]

Suh, J.H., Kim, Y.H., 2008. Extra-thoracic hematoma after minor blunt chest injury. Eur. J. Cardiothorac. Surg., 33(6): 1140. [doi:10.1016/j.ejcts.2008.03.005]

Takeshima, S., Hatori, N., Uryuda, Y., et al., 1997. A case report of the subclavian pseudoaneurysm due to blunt chest trauma without fracture. Nihon. Kyobu. Geka. Gakkai Zasshi, 45(11):1884-1888 (in Japanese).

Tomcsányi, I., Lónyay, T., Berentey, E., et al., 1978. Arteriovenous fistula of the internal mammary artery. Orv. Hetil., 119(8):469-471.

Walker, T.G., Salazar, G.M., Waltman, A.C., 2012. Angiographic evaluation and management of acute gastrointestinal hemorrhage. World J. Gastroenterol., 18(11):11911201. [doi:10.3748/wjg.v18.i11.1191]

Whigham, C.J.Jr., Fisher, R.G., Goodman, C.J., et al., 2002. Traumatic injury of the internal mammary artery: embolization versus surgical and nonoperative management. Emg. Radiol., 9(4):201-207.

Wilkinson, J., Jacob, T.D., Armitage, J., et al., 1993. Avulsion of the internal mammary artery caused by blunt trauma. Ann. Emerg. Med., 22(11):1762-1765. [doi:10.1016/ S0196-0644(05)81321-6]

Yeh, C.C., Hsieh, C.H., Wang, Y.C., et al., 2009. Concomitant aortic valve and internal mammary artery injuries in blunt chest trauma: report of a case. Surg. Today, 39(9): 790-794. [doi:10.1007/s00595-008-3915-3]

\section{中文椹要:}

\section{本文题目：钝性胸部损伤后内乳动脉损伤的评价}

Assessment of internal mammary artery injury after blunt chest trauma: a literature review

研究目的：评价钝性胸部损伤后内乳动脉损伤的发病率,出血情况和治疗效果。

创新要点: 通过分析患者由于钝性胸部损伤导致内乳动脉破裂的病情发展, 为快速诊断和治疗提供理论指 导，并首次探讨了内乳动脉损伤后出血部位的形成机制。

研究方法: 通过 MEDLINE 文献数据库共检索出 49 例由于钝性胸部损伤引起内乳动脉破裂的患者（1977 年 7 月至 2014 年 2 月), 进行了系统性分析。

重要结论: 在分析的 49 例患者中, 男性和左内乳动脉有更高的发病率。内乳动脉破裂出血能引起纵隔血 肿、血胸、假性动脉瘤、动静脉瘘和胸膜外血肿。其中 20 例患者给予栓塞治疗, 22 例选择外 科手术，4 例进行临床观察，3 例未描述治疗情况。内乳动脉损伤的不同程度和范围、临近的 静脉损伤以及胸膜的完整性决定了患者的出血类型。在患者的治疗中, 推荐快速诊断、彻底止 血、加强复苏和团队合作。

关键词组：针性损伤; 内乳动脉; 胸部 